\title{
Akinetic mutism and bilateral anterior cerebral artery occlusion
}

\author{
FRANK R. FREEMON \\ From the Department of Neurology, Marquette School of Medicine, Milwaukee, Wisconsin, U.S.A.
}

SUMMARY Three cases of bilateral anterior cerebral artery occlusion are presented with akinetic mutism. The anatomical distribution of the infarction in these patients combined with cases in the literature suggests that this syndrome can have a localizing value for the clinician. If increased intraventricular pressure is not present, the clinician can suspect a bilateral lesion of cingulate gyrus, medial nuclei of basal ganglia, and/or anterior and reticular nuclei of the thalamus.

Akinetic mutism is a disorder of consciousness characterized by unresponsiveness but with the superficial appearance of alertness. The patient's eyes are open and he may seem to look at the examiner but he neither speaks nor moves, nor is the examiner able to communicate with the patient. Poppen (1939) and Dandy (1946) each reported a case of akinetic mutism after operative sacrifice of both anterior cerebral arteries. Skultety (1968) described a patient who developed akinetic mutism after the clipping of the right anterior cerebral artery during the removal of a falx meningioma with apparent postoperative thrombosis in the left anterior cerebral artery. This communication describes three cases of akinetic mutism associated with spontaneous bilateral anterior cerebral artery occlusion and discusses the neuroanatomical substrate which may underlie the appearance of this syndrome.

\section{CASE 1}

A 68 year old retired depressed white male was admitted to the surgical service because of a self-inflicted minor gunshot wound to the chest. The only significant past history was a myocardial infarction 13 years previously. After successful treatment of his chest wound the patient was transferred to the psychiatric service because of continued suicidal thoughts and statements. One morning a week later he awoke feeling unusually 'groggy' as he told his room-mate. On his way to the bathroom the patient fell and could not arise. When he was examined his eyes were open but he could not speak or follow commands. The doll's head manoeuvre showed extraocular movements to be full. Pupils were equal and reactive to light. Gag reflex was present as were corneal reflexes. A slight plastic rigidity was present in all limbs. The only move- ment elicitable was a slight withdrawal of each limb to deep pain stimulation. However, if the patient's arm was held over his face and allowed to drop, it usually fell in such a way as to miss his face. Tendon reflexes were bilaterally symmetrical and hyperactive, particularly in the lower extremities with sustained clonus at both ankles. Bilateral Babinski signs were present, as were snout and grasp reflexes. The patient would look at the examiner and would follow him with his eyes. Several attempts to communicate with the patient using eye movements or eye blinks as signals were entirely unsuccessful. Within an hour after the insult, an electroencephalogram was performed which showed low voltage $2-2 \frac{1}{2} \mathrm{~Hz}$ generalized activity. A lumbar puncture showed an opening pressure of $140 \mathrm{~mm} \mathrm{CSF}$ and a closing pressure of $120 \mathrm{~mm} \mathrm{CSF}$; glucose was $77 \mathrm{mg}$ and protein $45 \mathrm{mg} / 100 \mathrm{ml}$. There were no cells in the CSF and there was no xanthochromia. The next morning the patient had lost his superficial appearance of alertness. His eyes were closed and his musculature was flaccid unless he was stimulated at which time he became rigidly opisthotonic with extension of legs and arms, with flexion at the wrists. He had CheyneStokes respiration with an apnoeic period of 20 seconds. At this time the pupils remained equal and reactive, extraocular movements were intact as estimated by the doll's head manoeuvre, and caloric examination showed conjugate tonic deviation of the eyes toward the side of the cold water. The patient died 10 days later.

NEUROPATHOLOGICAL FINDINGS External examination revealed bilateral softening from the frontal pole to the inferior occipital region with slight clouding and thickening of the overlying meninges. Coronal sections showed severe infarction on the left, involving the entire frontoparietal and temporal cortex extending through subcortical white matter to the basal ganglia, including the head of the caudate nucleus but sparing the thalamus. The area of infarction was more patchy on the right but extended throughout the area of distribution of the 
anterior and middle cerebral arteries. The occipital regions, the cerebellum, and the brain-stem were normal both grossly and microscopically. Microscopic examination in the infarcted area showed loss of parenchyma, necrosis of vessels, and accumulation of polymorphonuclear leucocytes. The blood vessels of the circle of Willis were markedly atherosclerotic. The right internal carotid artery was small in size and was occluded by an old partially organized thrombus which showed extensive recanalization on microscopic examination. The left carotid artery near its bifurcation was occluded by a fresh thrombus which extended upward into the middle and anterior cerebral arteries as well as the anterior communicating and right anterior cerebral arteries. Microscopic examination revealed this to be a mixture of old and recent thrombosis with partial recanalization.

\section{CASE 2}

A 72 year old retired white carpenter in good health except for occasional dizzy spells suddenly became unconscious after supper, falling on the couch. The unresponsive patient was kept at a local nursing home for the next seven weeks. An electroencephalogram (EEG) during this period was locally interpreted as normal but was not available for review. When transferred to a Veteran's Administration hospital, the patient had an alert appearance but was unresponsive. His eyes were usually open and moved spontaneously as though he were looking around the room; they did not follow a moving object or person. He would not respond to auditory commands including those associated with eye movements. No attempt was made to communicate with the patient by means of eye blinks or movements. To superficial tactile stimulation the patient gave no response but to deep pain stimulation on the right side of the body or face only, he made writhing and purposeless movements of the right arm and leg. Unrelated to stimulation or commands, the patient made occasional, apparently spontaneous, slight movements of the right arm. Muscle tone was markedly increased in the right arm and leg. There was a left Hoffman sign, a left Babinski sign, and hyperactive tendon reflexes on the left. A snout reflex was present as was a grasp reflex of the right hand. The patient died the following day.

NEUROPATHOLOGICAL FINDINGS External examination showed a sunken haemorrhagic area in the distribution of the right middle cerebral artery. Coronal sectioning revealed an infarction in the right anterior and middle cerebral artery distribution involving frontoparietotemporal cortex, basal ganglia, including the head of the caudate nucleus, and internal capsule but sparing thalamus. On the left a cystic degeneration involved the head of the caudate nucleus, the medial putamen, and the anterior limb of the internal capsule sparing overlying cortex. There were no other abnormalities. Microscopic examination of the infarcted areas showed tissue necrosis with reactive gliosis. Examination of cerebral vessels revealed moderate atherosclerosis but no apparent occlusion or thrombosis. Figure 1 shows the pathological specimen in this patient.

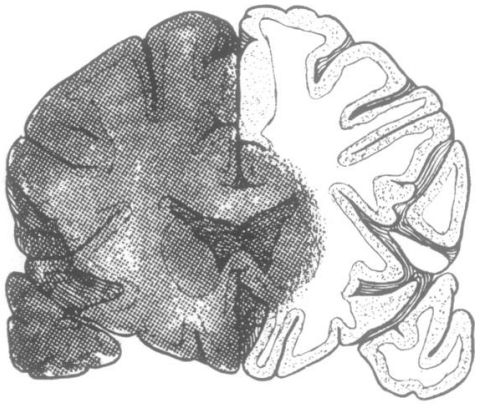

CASE 3

A 62 year old Negro diabetic pulpwood labourer on insulin for 10 years was hospitalized in diabetic ketoacidosis. Seven years before admission the patient awoke with a slight left hemiparesis without any other symptoms; this left-sided weakness had improved but never completely cleared. For the three days before admission, the patient increased his food and water intake without a change in his daily dose of 70 units of lente-insulin and in the absence of infection or trauma. On the day of admission, he became increasingly confused and finally became unconscious. No hypoglycaemia was noted during insulin and fluid treatment of the ketoacidosis. On the third hospital day, the patient opened his eyes but remained unresponsive. His eyes moved conjugately as though he were looking about the room but without following moving objects. The patient failed to respond to any auditory or visual command, except on one occasion when he opened his mouth after the oral command to perform this movement. Pain stimulation caused slight withdrawal movements of the appropriate extremity. Pupils were equal and reactive. Corneal reflexes were bi- $\bar{N}$ laterally absent. The 'doll's head' manoeuvre showed $O$ complete conjugate eye movements. Caloric stimulation $N$ caused conjugate tonic deviation of the eyes toward the 
side of the cold water. Muscle tone was normal. Tendon reflexes were decreased and abdominal reflexes were absent. A Babinski sign was present on the left but not on the right. A lumbar puncture showed normal pressure with CSF protein of 54 and glucose of $109 \mathrm{mg} / 100 \mathrm{ml}$. An EEG showed diffuse theta and delta activity. The patient died five weeks after admission without ever regaining consciousness. About three weeks before he died, he closed his eyes and lost the alert appearance he had demonstrated previously.

NEUROPATHOLOGICAL FINDINGS External examination of the brain revealed only atherosclerotic distortion of the circle of Willis. Coronal sectioning uncovered an area of infarction in both hemispheres in the area of supply of both anterior cerebral arteries. The infarcted area included the head of the caudate nucleus, the anterior and medial portion of the globus pallidus, the septal nucleus, and the anterior thalamus. The right anterior cerebral artery was occluded by atheroma just distal to the anterior communicating artery, probably involving the origin of the recurrent branch of Heubner. Narrowing and thrombotic occlusion were present in the left anterior cerebral artery at the genu of the corpus callosum. There were no other brain abnormalities. Microscopic examination in the area of infarction showed large numbers of macrophages and pleomorphic microglia. Sections of both anterior cerebral arteries showed occlusions in the process of recanalization. Figure 2 shows the distribution of the lesion in this patient.

\section{DISCUSSION}

These three patients presented with a disorder of consciousness characterized by a superficial appearance of alertness with open eyes, but with no speech and no movement save a slow withdrawal from painful stimuli. Case 1 had infarction in both anterior and middle cerebral artery distributions. Perhaps the bilateral anterior cerebral infarction occurred first and the bilateral middle cerebral infarction happened on the following day, changing the clinical picture from akinetic mutism to decerebrate coma. Case 2 had an infarction in the distribution of both anterior cerebral arteries and the right middle cerebral artery. Presumably involvement of the latter vessel caused the reflex and tone changes in the left arm. Case 3 had pathology restricted to infarction in the distribution of both anterior cerebral arteries; presumably these occlusions occurred during the patient's dehydrated ketoacidotic state, because when his blood chemistry returned to normal, his clinical state changed from coma to akinetic mutism.

These three patients and the ligation cases of Poppen (1939), Dandy (1945), and Skultety (1968) suggest that neuroanatomical structures which receive their vascular supply from the anterior cerebral artery can produce akinetic mutism when bilaterally
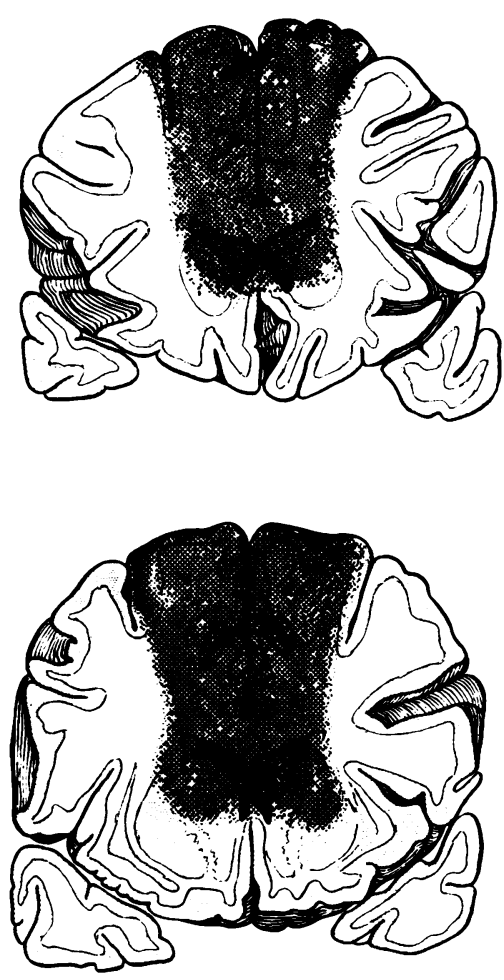

FIG. 2. The distribution of infarcted area in case 3.

damaged. Though there is some individual variation, the anterior cerebral artery usually supplies the cingulate cortex via its callosal branches, the medial surface of the frontal lobe via frontopolar and other branches, the medial portion of the head of the caudate nucleus, the septal nucleus and the parolfactory area through perforating branches, and the medial caudate, medial putamen, and portions of the internal capsule via the recurrent branch of Heubner (Alexander, 1942; Gillilan, 1968). Previous studies have implicated damage to the anterior cingulate gyrus or to the head of the caudate nucleus in the production of akinetic mutism. Nielsen and Jacob (1951) recorded a case of suspected embolic infarction with haemorrhage, apparently restricted to both anterior cingulate gyri and the corpus callosum. Localization in this case was complicated by increased intracranial pressure with papilloedema. Barris and Schuman (1953) also reported a case of akinetic mutism with infarction in both anterior cingulate gyri. However, many other patients have undergone surgical ligation of both anterior cerebral arteries at the genu of the corpus callosum, which usually causes infarction in the anterior cingulate 
gyrus but not in basal ganglia, without suffering akinetic mutism (Poppen, 1939; Meyers, 1951). In addition, patients fail to develop akinetic mutism after therapeutic bilateral anterior cingulotomies (Livingston, 1953; Ballantine, Cassidy, Flanagan, and Marino, 1967). In both man and experimental animals, bilateral destructive lesions which include the head of the caudate nucleus have been associated with behavioural changes similar to akinetic mutism. Marinesco and Draganesco (1929) reported a 4 year old epileptic who suffered anoxia during a seizure. For the next 18 months both speech and purposeful movement remained absent though the patient's eyes were open. Necropsy disclosed severe neuronal necrosis bilaterally in putamen and caudate nuclei with only mild changes in globus pallidus and patchy laminar necrosis of the cerebral cortex. Hawke and Donohue (1951) described a child with bilateral necrosis of the caudate nucleus, putamen, and globus pallidus developing during the course of otitis media without any known episode of anoxia. During two months of survival the child neither spoke nor responded to commands, although she would occasionally cry and withdraw from a painful stimulus. She followed an object with her eyes. On the other hand, Meyers (1942) described a case of bilateral surgical extirpation of the caudate nucleus for the treatment of Parkinson's disease which did not produce akinetic mutism. Postoperatively the patient had a transient hallucinatory state and 'became difficult to manage on the ward' but 'neurological and intellectual functions were intact'. At home, the patient's wife related that he had become bellicose and irritable and 'aged' considerably in the following months. Experimental bilateral damage in caudate nucleus of experimental animals usually produces hyperactivity (Richter and Hines, 1938; Mettler and Mettler, 1942) but sometimes produces a transitory state not too unlike akinetic mutism. For example, Gybels, Meulders, Callens, and Colle (1967) created bilateral electrolytic lesions in cats limited to the head of the caudate nucleus and for the next five days the animals were catatonic and abnormal positions could be imposed on them for several minutes'. Mettler (1945) reported several monkeys who became hypokinetic after bilateral surgical destruction of caudate nuclei and overlying frontal cortex. For example, rhesus J65 'often remained motionless in some pose suggestive of suspended animation' and rhesus J71 'periodically stopped in an arrested position' or 'sat indefinitely without eating'.

A large number of patients exhibiting akinetic mutism with no damage in any structure supplied by the anterior cerebral artery have been reported. In fact, the great variety of neuroanatomical areas which have been proposed as a site for the production of akinetic mutism has caused some workers to despair. In speaking of akinetic mutism, Skultety (1968) concluded: 'The syndrome has been reported with lesions of the third ventricle, thalamus, basal ganglia, midbrain, anterior cingulate gyrus, and also associated with basilar artery occlusion, central pontine myelinolysis, and obstructive hydrocephalus. From this, it would appear that the syndrome has little localizing value.' The basic thesis of this communication is that akinetic mutism can serve as a localizing syndrome if one differentiates true akinetic mutism, a disorder of consciousness, from pseudoakinetic mutism, a severe paralysis, and if one can rule out obstructive hydrocephalus with increased intraventricular pressure.

Lesions of the basis pontis interfere with motor outflow to all facial and body musculature below the eyes. This profound paralysis produces a patient who can neither speak nor move, but whose consciousness is unimpaired, as can be tested by devising a system in which eye blinks signal 'yes' or 'no'. This syndrome has been called the ventral pontine syndrome, the de-efference syndrome, the locked-in syndrome, a state resembling akinetic mutism (Kemper and Romanul, 1967), the syndrome of Noirtier de Villefort, or pseudo-akinetic mutism?

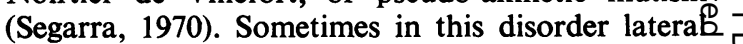
eye movements are also paralysed, leaving onls, vertical movements intact. The electroencephalo graph in pseudo-akinetic mutism shows a normat waking record, while in true akinetic mutism general 등. 뜬 ized slow activity is usually present. The majop $\vec{\theta}$ differentiating factor is the state of consciousness; one can communicate with a pseudo-akinetic mute through an eye blink code but not with a patient suffering from true akinetic mutism. To complicate matters, sometimes akinetic mutism varies in its depth or purity so that an incomplete case can be roused at times to communicate with eye or finger movements, or even with speech.

Messert, Henke, and Langheim (1966) have synthesized many cases of akinetic mutism of varying aetiologies into a syndrome of obstructive hydrocephalus with increased intraventricular pressure. Their patients with obstructive hydrocephalus of different aetiologies developed a symptom complex beginning with pyramidal tract signs in the lower extremities and progressing through a gait disorder characterized as frontal lobe ataxia or the gait apraxia of Meyer and Barron (1960) to akinetic mutism, which they considered a global apraxia. This progression could be reversed by decreasing intraventricular pressure with neurosurgical shunt procedures. Reversible dysfunction of periventricular structures due to occult or obstructive hydrocephalus could explain the occurrence of akinetic 
mutism in a wide variety of disorders including normal pressure hydrocephalus (Hakim and Adams, 1965), tumours of the aqueduct of Sylvius (Daly and Love, 1958), and third ventricular cysts (Cairns, Oldfield, Pennybacker, and Whitteridge, 1941).

Even after cases of apparent akinetic mutism associated with lesions of ventral pons or increased intraventricular pressure are discarded, several patients with true akinetic mutism remain in which no lesion in the distribution of the anterior cerebral artery was described at necropsy. Cravioto, Silberman, and Feigin (1960) and Denny-Brown (1962) each described a case of true akinetic mutism after carbon monoxide poisoning with pathology apparently restricted to the globus pallidus on both sides. These cases must have had submicroscopic pathology in other areas, since bilateral pallidectomies performed for the treatment of movement disorders do not produce akinetic mutism. Cairns (1952) mentioned a case of akinetic mutism associated with bilateral haemorrhagic lesions in the dorsomedial nucleus of thalamus but full pathological details were not given. Segarra (1970) has clearly described true akinetic mutism in several patients with infarction of bilateral midline and reticular thalamic nuclei. These cases differed from most previous patients with akinetic mutism in that they were somnolent or drowsy with eyes closed during most of the day and only when they were roused with minimal stimuli such as the calling of their names did the full picture of akinetic mutism occur. With regard to experimental lesions, Meyer and Hunter (1952) produced an akinetic state in cats and monkeys with bilateral lesions in the anterior nucleus of the thalamus. On the other hand, bilateral lesions in anterior and dorsomedial nuclei of the thalamus inflicted for the treatment of psychiatric disorders have not produced akinetic mutism (Spiegel, Wycis, Freed, and Orchinik, 1953).

In summary, the syndrome of akinetic mutism can have localizing value to the clinician. If he can rule out massive destruction of motor outflow pathways causing a disorder resembling akinetic mutism but preserving consciousness and if third and lateral ventricular dilatation are not present, then he can suspect bilateral pathology in the cingulate cortex, medial basal ganglia, and/or anterior and medial nuclei of the thalamus. These structures are, of course, anatomically interrelated.

\section{CONCLUSIONS}

The cases presented in this paper and several previous cases in the literature suggest that bilateral lesions of the head of the caudate nucleus associated with destruction of medial putamen, septum, medial frontal cortex, and cingulate cortex can result in akinetic mutism. From reported cases, it appears that bilateral lesions which include globus pallidus and anterior, dorsomedial, and reticular nuclei of the thalamus can also cause the syndrome. The syndrome can also result from obstructive or normal pressure hydrocephalus with third and lateral ventricular dilatation. If the clinician differentiates this disorder from the paralytic disorder of pseudo-akinetic mutism which preserves consciousness, then the syndrome of akinetic mutism can have localizing value.

\section{REFERENCES}

Alexander, L. (1942). The vascular supply of the striopallidum. Res. Publ. Ass. nerv. ment. Dis., 21, 77-132.

Ballantine, H. T. Jr., Cassidy, W. L., Flanagan, N. B., and Marino, R., Jr. (1967). Stereotaxic anterior cingulotomy for neuropsychiatric illness and intractable pain. $J$. Neurosurg., 26, 488-495.

Barris, R. W., and Schuman, H. R. (1953). Bilateral anterior cingulate gyrus lesions. Syndrome of the anterior cingulate gyri. Neurology (Minneap.), 3, 44-52.

Cairns, H. (1952). Disturbances of consciousness with lesions of the brain-stem and diencephalon. Brain, 75, 109-146.

Cairns, H., Oldfield, R. C., Pennybacker, J. B., and Whitteridge, D. (1941). Akinetic mutism with an epidermoid cyst of the 3rd ventricle. Brain, 64, 273-290.

Cravioto, H., Silberman, J., and Feigin, I. (1960). A clinical and pathological study of akinetic mutism. Neurology (Minneap.), 10, 10-21.

Daly, D. D., and Love, J. G. (1958). Akinetic mutism. Neurology (Minneap.), 8, 238-242.

Dandy, W. E. (1946). The location of the conscious center in the brain-the corpus striatum. Bull.Johns Hopk. Hosp., 79, 34-58.

Denny-Brown, D. (1962). The Basal Ganglia and their Relation to Disorders of Movement, p. 58. Clarendon Press: London.

Gillilan, L. A. (1968). The arterial and venous blood supplies to the forebrain (including the internal capsule) of primates. Neurology (Minneap.), 18, 653-670.

Gybels, J., Meulders, M., Callens, M., and Colle, J. (1967). Disturbances of visuo-motor integration in cats with small lesions of the caudate nucleus. Arch. intern. Physiol. Biochim., 75, 283-302.

Hakim, S., and Adams, R. D. (1965). The special clinical problem of symptomatic hydrocephalus with normal cerebrospinal fluid pressure. Observations on cerebrospinal fluid hydrodynamics. J. neurol. Sci., 2, 307-327.

Hawke, W. A., and Donohue, W. L. (1951). Bilateral symmetrical necrosis of the corpora striata. J. nerv. ment. Dis., 113, 20-39.

Kemper, T. L., and Romanul, F. C. A. (1967). State resembling akinetic mutism in basilar artery occlusion. Neurology (Minneap.), 17, 74-80.

Livingston, K. E. (1953). Cingulate cortex isolation for the treatment of psychoses and psychoneuroses. Res. Publ. Ass. nerv. ment. Dis., 31, 374-378.

Marinesco, G., and Draganesco, S. (1929). Contribution anatomo-clinique à l'étude du syndrome du Foerster. Encéphale, 24, 685-699. 
Messert, B., Henke, T. K., and Langheim, W. (1966). Syndrome of akinetic mutism associated with obstructive hydrocephalus. Neurology (Minneap.), 16, 635-649.

Mettler, F. A. (1945). Effects of bilateral simultaneous subcortical lesions in the primate. J. Neuropath. exp. Neurol., 4, 99-122.

Mettler, F. A., and Mettler, C. C. (1942). The effects of striatal injury. Brain, 65, 242-255.

Meyer, J. S., and Barron, D. W. (1960). Apraxia of gait: a clinico-physiological study. Brain, 83, 261-284.

Meyer, J. S., and Hunter, J. (1952). Behaviour deficits following diencephalic lesions. Neurology (Minneap.), 2, 112-130.

Meyers, R. (1942). The modification of alternating tremors, rigidity and festination by surgery of the basal ganglia. Res. Publ. Ass. nerv. ment. Dis., 21, 602-665.

Meyers, R. (1951). Dandy's striatal theory of 'The center of consciousness'. Surgical evidence and logical analysis indicating its improbability. Arch. Neurol. Psychiat. (Chic.), 65, 659-671.
Nielsen, J. M., and Jacobs, L. L. (1951). Bilateral lesions of the anterior cingulate gyri: report of a case. Bull. Los Angeles neurol. Soc., 16, 231-234.

Poppen, J. L. (1939). Ligation of the left anterior cerebral artery: its hazards and the means of avoidance of its complications. Arch. Neurol. Psychiat. (Chic.), 41, 495-503.

Richter, C. P., and Hines, M. (1938). Increased spontaneous activity produced in monkeys by brain lesions. Brain, 61, $1-16$.

Segarra, J. M. (1970). Cerebral vascular disease and behavior. I. The syndrome of the mesencephalic artery (basilar artery bifurcation). Arch. Neurol. (Chic.), 22, 408-418.

Skultety, F. M. (1968). Clinical and experimental aspects of akinetic mutism. Arch. Neurol. (Chic.), 19, 1-14.

Spiegel, E. A., Wycis, H. T., Freed, H., and Orchinik, C. (1953). Thalamotomy and hypothalamotomy for the treatment of psychoses. Res. Publ. Ass. nerv. ment. Dis., 31, 379-391. 